\title{
Low Back Pain
}

\author{
Luigi Manfrè and Johan Van Goethem
}

\section{Learning Objectives}

- To understand the very variable causes of low back pain.

- To appreciate the mostly benign clinical course of low back pain.

- To critically assess the critical relevance of imaging findings.

\section{Key Points}

- Section 18.1: Discogenic Low Back Pain (DLBP): The relationship between disc abnormalities and clinical symptoms is still debated.

- Section 18.2: Instability: Microinstability presents with a sensation of instability felt by the patient and objectively observed impaired muscle control.

- Section 18.3: Radicular Pain: Disc fragments may migrate behind the vertebral body and be overlooked in limited imaging protocols.

- Section 18.4: Sacroiliac Joint Disease: Chronic sacroiliac joint arthritis frequently is the cause of low back pain, particularly in women.

- Section 18.5: Failed Back Surgery Syndrome: Epidural fibrosis is one of the most common causes of low back pain after surgery.

- Section 18.6: Vertebrogenic Low Back Pain: Not even Modic 1 abnormalities represent an independent predictor of low back pain. They may be present in asymptomatic individuals.

\section{Manfrè $(\bowtie)$}

Unità Operativa di Interventistica Spinale Mini-Invasiva dell' Istituto Oncologico del Mediterraneo-IOM, Catania, Italy

J. Van Goethem

Department of Biomedical Sciences, Antwerp University Hospital,

Antwerp, Belgium
LBP is one of the most widespread and common diseases, some statistics report that about two-thirds of adults suffer from LBP at some point in their life, being second only to upper respiratory tract [1]. It is the greatest contributor to years lived in disability throughout much of the world and the first cause of everyday life activity limitation as well as absence from work [2]. The 2010 Global Burden of Disease Study considers LBP one of the ten diseases occurring worldwide [3], the prevalence of LBP is considered among $60-70 \%$ in European and US countries, with a recent increase even in younger population and a peak at 35-55 years of age [4-7]. The incidence of LBP has been documented in $50 \%$ of people having light physical activity and in more than $70 \%$ of those performing heavy activities and is the most frequent cause of cessation of activity in patients younger than 45 years old [8]. Moreover, this condition has deep relationship with other pathologies such as depression, anxiety, and sleep disturbances [9].

Only 7-8\% of patients with LBP have symptoms persisting over 2 weeks and just $1 \%$ need a real treatment: among them, symptoms usually improve rapidly in 1 month [8], 1/3 of them having — on the contrary - a persistent moderate to severe LBP after 1 year [10]. The etiology of chronic low back pain remains generally unknown or nonspecific (up to 85\%): there are several known causes of LBP syndrome (i.e., different from LBP) as age, psychosocial aspects (depression, stress, stop working), education (increasing LBP in low-educational status) [11], stress overload (heavy working or sport activities), smoking (the nicotine being a vascular degeneration agent reducing physiological disc nutrition), even genetic cause (74\% heritability in twins), and obesity (body mass index of more than $30 \mathrm{~kg} / \mathrm{m}^{2}$ ) [12]. Obesity in early adult age definitely increases the risk of nonspecific LBP as well as degenerative changes in lumbar spine [13].

Pure LBP conversely is generally related to pathologic degeneration of several structures involved in the spinal unit, as lumbar intervertebral disc, facet joints, muscular fascia, sacroiliac joints, ligaments, nerve root, and muscles directly [14]. Mechanical, traumatic, nutritional, and genetic factors all play a role in the cascade of spine degeneration. 
The role of imaging is to provide accurate morphologic information and influence therapeutic decision making. A necessary component, which connects these two purposes, is accurate natural history data. This is critical as, according to Rego et al. [15], up to $40 \%$ of patients exhibited no indications to imaging. Up to about $59 \%$ of lumbar spine MRI examinations requested among different social and economic settings have been deemed as inappropriate, depending on the evaluation method [16-19]. Of all lumbar and thoracic spine CT examinations in young patients, up to $77 \%$ were judged as inappropriate; therefore, such examinations are responsible for an unjustified cost for individuals or health systems and unnecessary radiation exposure [20].

Any study looking at the natural history of degenerative disc disease, prognostic value of imaging, or its effect on therapeutic decision making will be confounded by the high prevalence of morphologic change in the asymptomatic population [21-23]. Twenty to twenty-eight percent of asymptomatic patients demonstrate disc herniation and the majority have evidence of additional degenerative disc disease [21-23]. These findings are not only non-predictive in the moment, but prospectively as well. In a 7-year follow-up of a patient group with back pain [24], the original MR findings were not predictive of the development or duration of low back pain.

\subsection{Discogenic Low Back Pain (DLBP)}

Studies that demonstrate innervation to the intervertebral disc provide evidence that may account for instances of discogenic low back pain [25]. It was revealed that innervation of the inner disc was observed only in painful discs, not in normal control discs [26, 27]. Moreover, stimulation of peridiscal nerve plexus widely contributes to disc pain generation. Though discography has been used in the past as gold standard in proving the existence of a discogenic pain, today a simple intra-discal injection of sterile solution is considered also [28].

MR imaging findings that correlate with painful discs on discography are those typical for disc degeneration, mainly signal loss of the disc on T2-WI, but also loss of disc height, the presence of a hyperintensity zone (HIZ), and Modic changes [29].

The hyperintensity zone (HIZ) is a localized region of high signal intensity on T2-WI within the annulus fibrosus. Histopathologically, these lesions represent replacement of the normal lamellar structure by a disorganized, vascularized granulation tissue consisting of small round cells, fibroblasts, and newly formed blood vessels around tears that extend from the nucleus pulposus to the outer region of the annulus fibrosus [30]. Originally the presence of a HIZ was strongly correlated with a painful disc on discography [31]. This correlation has confirmed in multiple later studies, but was also questioned in a few other studies. In general, the association between an annular tear on MR images and low back pain is unclear.

\subsection{Spinal Instability}

Lumbar instability is one of the most common causes for chronic low back pain (LBP); in particular, it is the main cause of LBP in young patients, especially in athletes and overweight population, who are subjected to local extra stress.

The biomechanical alterations are related to the intervertebral disc degeneration that loses the physiological capacity to adsorb the applied load and to apply torsion resistance, with consequent change in the vector forces of the spinal unit, and dynamic overload of the posterior arches elements, especially of the zygapophyseal joints.

From a biomechanical point of view, the instability of a vertebral motion segment is defined as an abnormal reaction to applied loads with an increasing range of motion (ROM). The neutral zone (NZ), the displacement between the neutral position and the initiation point of spinal resistance to physiological motion, is considered to be a better indicator of lumbar instability than the ROM $[32,33]$.

The concept of vertebral instability has evolved in the last years, and the new concept of "microinstability" was recently introduced: Microinstability can be defined as a pure motion/ biomechanical dysfunctional syndrome with no or minimal anatomical changes, in absence of spondylolisthesis.

Microinstability lumbar syndromes present with a subjective sensation of instability felt by the patient and an objectively observed impaired muscle control. In the absence of an adequate control by segmental muscles inserting directly on the spine, patients tend to stabilize the dysfunctional MS through muscles which provide a compensatory global trunk stabilization for which high levels of intra-abdominal pressure are generated even during lowload tasks [34].

In flexion microinstability, the most frequent type, signs suggestive of altered movement control within the neutral zone are a good range of spinal mobility, but with a "painful arc" and the inability to return to erect posture from forward bending without assistance. Patients are unable to maintain semi-flexed postures. A loss of lumbar lordosis during standing can be observed at the level of the unstable MS along with a greater flexion during forward bending [35].

Kirkaldy-Willis originally described the cascade of degenerative instability, consisting of three phases: an initial dysfunction, an instability time, and a final restabilization [36]. Instability begins with a dysfunctional time, marked by intermittent nonspecific pain, associated with initial and slight morphological changes, followed by a stage of so-called unstable dysfunction with pathological alterations affecting the constitutive elements of the motor spinal unit. At this stage pain becomes more persistent [36, 37] or chronic. This first phase of the degeneration cascade in absence of spondylolisthesis in flexion-extension radiography can be considered as the equivalent of the clinical syndrome previously defined as microinstability. 
In the final phase of "restabilization," the fibrosis of the joint capsules, the formation of osteophytes, the marked disc collapse, and the radial expansive remodeling of vertebral bodies lead to an overall increase in stiffness along with hypomobility. During this stage functional limitation and stiffness prevail; it can appear as neurological deficits, while spinal pain can eventually fade or subside [36].

Unfortunately, there are no validated clinical signs for diagnosing degenerative instability, with a large overlap of motion patterns between symptomatic and normal individuals, which renders difficult to state any cut-off to distinguish normality and instability [38].

Kotilainen and Valtonen described the three criteria for instability:

Failure to full return from the bent position because of a sudden attack of low back pain (i.e., instability catch); inability to get a raised, straightened leg to move down and suddenly drops the leg due to a sharp pain in the low back (i.e., painful catch); and anxiety resulting from a sensation of collapse of the low back because of a sudden attack of back pain during movement (i.e., apprehension) [39].

Moreover, no exam available allows to detect an active segmental hypermobility, in conditions where a microinstability is suspected.

Lower back pain which originates from the facet joints has not been shown by studies to relate to radiological or pathological changes $[40,41]$. The value of plain radiographs, computed tomography, and magnetic resonance imaging scans in diagnosing facet joint disease remains inconclusive [42]; furthermore, they are not able to predict the patients who would respond to controlled diagnostic blocks of the facet joint so imaging studies have their greatest value in the exclusion of other pathological conditions.

Bone scintigraphy with single photon emission computed tomography (SPECT) is more sensitive in detecting facet joint lesions and allows more accurate anatomical localization. A recent study suggested that SPECT could help to identify patients with low back pain who would benefit from facet joint injections [43].

Facet joint block (FJB) is an indispensable diagnostic instrument in order to distinguish painful from painless facet joints, and to plan the intervention strategy.

The procedure is safe, valid, and reliable; the risk of FJB is very low and complications are rare, although there are case reports on infections [44-46].

Saal describes as the gold standard of diagnostic FJB the highly controlled (CT, MRI) FJB at the median nerve branch (MBB) [47]. The CT or MRI guidance is responsible for the highest specificity of the test [47].

The specificity of the FJB is however not high, with falsepositive rates ranging from $25 \%$ to $38 \%$ [48-50]. Standard blockade injections of the medial branches seem to anesthetize the joint and also the muscles, ligaments, and periosteum they innervate [49].

\subsection{Radicular Pain}

Acute lumbar disc herniation is the most common cause of acute radicular leg pain. After excluding emergent causes, such as cauda equina syndrome, epidural abscess, fracture, or malignancy, a six-week trial of conservative management is indicated [51]. Patients should be advised to stay active. If symptoms persist after 6 weeks, or if there is worsening neurologic function, imaging and invasive procedures may be considered. Most patients with lumbar disc herniation improve over 6 weeks.

If a disc herniation is identified that correlates with physical findings, surgical discectomy may improve symptoms more quickly than continued conservative management. Epidural steroid injections can also provide short-term relief [51].

Herniated discs are more easily detected with MRI than with CT for many reasons. Firstly, MR imaging allows visualization of the complete lumbar (or cervical or thoracic) spine in one examination. Secondly, sagittal images also depict the spinal canal in between intervertebral disc spaces. It is not unusual for a disc fragment to migrate (or extend) into the area behind the vertebral body. Some of these migrated discs can be missed on CT if axial slices are limited to the intervertebral disc spaces examined. Finally, the intrinsic tissue contrast is usually better on MR. Especially the lumbosacral region can be hard to assess on $\mathrm{CT}$ due to beam hardening, especially in larger patients.

Chronic radicular pain can be caused by a disc herniation, but also vertebral osteophytic spurs, degenerative facet spurs and facet hypertrophy, and degenerative foraminal stenosis are an important cause of nerve root irritation. Foraminal nerve root entrapment is best visualized on T1-weighted MRI where the high contrast between fat tissue and the nerve root sheath is of great help. Usually a combination of hypertrophic degenerative facets with osteophytic spurs posteriorly, and vertebral osteophytes and/or disc herniation anteriorly diminishes the anteroposterior diameter of the foramen. Foraminal height is lessened by degenerative disc disease and subsequent disc height loss. Whenever the normal rounded (oval) appearance of the nerve root sheath is lost in combination with loss of the surrounding fat tissue, nerve root compression should be considered.

\subsection{Sacroiliac Joint Disease}

One frequent (5-25\% of all LBP causes) [52-55] and frequently misunderstood cause of LBP in adult males, particularly females, is the chronic sacroiliac joint arthritis secondary to acquired focal instability. The sacroiliac joint (SIJ) is the strongest and richest joint in human body as for ligaments (anterior sacroiliac, interosseous, sacrospinous, and sacrotuberous) and muscles (gluteus maximus, piriformis, and biceps femoris), concurring to stabilize the joint [56]. Despite 
the great stability of this joint, there are several conditions that can reduce the stability of SIJ, generating chronic pain in a patient. SIJ ligaments are weaker in female patients as they are estrogen dependent, preparing the sacrum to the delivery nutation: as a consequence, postpartum chronic pain at the level of the sacrum can occur even after months after the delivery [57]. Another frequent cause of SI chronic pain is biomechanical changes in lumbar spinal unit mobility, secondary to surgical procedures like posterior interbody fixation (PIF)—generally performed in case of lumbar instability but conversely generating sacral instability too: it has been calculated that $75 \%$ of patients underwent PIF treatment suffer from painful SIJ instability in 5 years $[58,59]$. Clinical symptoms related to SIJ disease are numerous, and no specific clinical sign supports the diagnosis. This uncommon uselessness of clinical symptoms analysis is related to the complexity of SIJ innervation, as the posterior surface of the joint receives collaterals from L3 to S4 dorsal rami [60], while anterior articulation is supplied by L2 to S2 nerves [61, 62]. Consequently, SIJ syndrome is responsible for pain referred in several different areas of the body, as the lower limbs, pelvis, coxo-femoral area, buttock, and abdomen, overlaying other common causes of radicular pain. Even if several physical maneuvers are suggested to evocate the pain and propose a SIJ disease, diagnosis and neuroradiological examinations (MRI, bone scanning, SPECT-CT) can show focal SIJ abnormalities proposing a SIJ syndrome, only diagnostic block of the SIJ injecting intra-articular anesthetics (lidocaine) is considered the gold standard method to confirm the disease [63].

\subsection{Failed Back Surgery Syndrome}

Failed back surgery syndrome (FBSS) is one of the most frequent causes of back pain in patient underwent surgical treatment, the etiology being controversial and complex. Epidural fibrosis is generally considered one of the most common causes of LBP after surgery, with patients having extensive epidural scars having more frequent LBP and radicular pain that those with mild epidural fibrosis [64]. Moreover, epidural scars are responsible for neurological impairment demonstrated by electrophysiology and nerve root tethering as well as nerve inflammation induced by high local cytokines, and other inflammatory agent level has been described $[65,66]$. In FBSS, the pain moves from a mechanic/inflammatory origin through a neuropathic pain: patients affected by it suffer from an increased sensitivity and responsiveness of receptors that generate an amplified reaction to mild algogenous stimuli ("hyperalgesia") and/ or misinterpretation of stimuli coming from non-nociceptive receptors ("allodynia"), generally related to abnormal activation of non-neuronal cells as microglia, together with changes in local pain neurotransmitter molecules, increasing pain feeling [67].

\subsection{Vertebrogenic Low Back Pain}

Vertebral body endplates are a significant source of nonspecific chronic low back pain.

Ample histologic, anatomic, and immunohistochemical evidence supports nociceptive role of the basivertebral nerve (BVN) in the pathogenesis of LBP in patients with endplates damage and Modic changes [68, 69].

As described by Antonacci the BVN enters the posterior vertebral body via the basivertebral foramen and arborizes near the center of the vertebral body, sending branches to innervate the superior and inferior endplates. These nerve endings have been shown to proliferate in damaged and degenerated endplates and can be classified as pain fibers: they are PGP 9.5-positive and express Substance P and Trk-A receptors [70].

Many previous studies suggest that Modic type 1, that indicates edema and inflammation, is associated with LBP and has a stronger association with pain in comparison to Modic type 2, since pain decreases as Modic type 1 changes turns into Modic type 2. It is important to consider that Modic 1 is not an independent predictor of LBP, ad like other several degenerative changes have been shown to exist even in asymptomatic individuals [71-73].

Recent introduction of bone HDP SPECT/CT allows to distinguish incidental from clinically relevant findings, it is a hybrid imaging that allows the assessment of both morphology and bone physiology in a single study. It is possible to demonstrate the increased metabolic activity of the suspected MRI findings with high sensitivity: abnormalities become apparent early and sensitivity is higher than with computed tomography (CT) or standard radiography, allowing to treat patients suffering from Vertebrogenic pain with selective intraosseous BV ablation [74].

\subsection{Concluding Remarks}

In conclusion, low back pain remains an enigma with a poorly understood and variable pathogenesis, very often with a favorable outcome. Imaging findings quite often do not correlate with clinical symptoms, although there have been advances in understanding them better. Radiologists need to critically evaluate any findings in order to avoid overtreatment.

Take Home Message

- A small proportion of patients with acute low back pain have symptoms persisting over 2 weeks and just $1 \%$ required active treatment, and the etiology of chronic low back pain remains generally unknown or nonspecific. Therefore, to critically discuss imaging findings in relation to clinical relevance is crucial. 


\section{References}

1. Deyo RA, Weinstein JN. Low back pain. N Engl J Med. 2001;344:363-70.

2. Hoy D, March L, Brooks P, et al. The global burden of low back pain: estimates from the global burden of disease 2010 study. Ann Rheum Dis. 2014;73:968-74.

3. Mazroa A, Mohammad A. Years lived with disability (YLDs) for 1160 sequelae of 289 diseases and injuries 1990-2010: a systematic analysis for the Global Burden of Disease Study 2010. Lancet. 2012;380(9859):2163-96.

4. Jeffries LJ, Milanese SF, Grimmer-Somers KA. Epidemiology of adolescent spinal pain: a systematic overview of the research literature. Spine. 2007;32(23):2630-7.

5. Taimela S, Kujala UM, Salminen JJ, Viljanen T. The prevalence of low back pain among children and adolescents: a nationwide, cohortbased questionnaire survey in Finland. Spine. 1997;22:1132-6.

6. Balague F, Troussier B, Salminen JJ. Non-specific low back pain in children and adolescents: risk factors. Eur Spine J. 1999;8:429-38.

7. Andersson GBJ. The epidemiology of spinal disorders. In: Frymoyer JW, editor. The adult spine: principles and practice Philadelphia: Lippincott-Raven; 1997. p. 93-141.

8. Pengel LH, Herbert RD, Maher CG. Acute low back pain: systematic review of its prognosis. BMJ. 2003;327:323.

9. Stubbs B, Koyanagi A, Thompson T, et al. The epidemiology of back pain and its relationship with depression, psychosis, anxiety, sleep disturbances, and stress sensitivity: data from 43 low- and middle-income countries. Gen Hosp Psychiatry. 2016;43:63-70.

10. Von Korff M, Saunders K. The course of back pain in primary care. Spine. 1996;21:2833-7.

11. Hoy D, Brooks P, Blyth F. The epidemiology of low back pain. Best Pract Res Clin Rheumatol. 2010;24:769-81.

12. Webb R, Brammah T, Lunt M, et al. Prevalence and predictors of intense, chronic, and disabling neck and back pain in the UK general population. Spine. 2003;28(11):1195-202.

13. Frilander H, Solovieva S, Mutanen P, Pihlajamäki H, Heliövaara M, Viikari-Juntura E. Role of over-weight and obesity in low back disorders among men: a longitudinal study with a life course approach. BMJ Open. 2015;5(8):e007805.

14. Manchikanti L, Hirsch JA, et al. Comprehensive evidence-based guidelines for interventional techniques in the management of chronic spinal pain. Pain Physician. 2009;12:699-802.

15. Rego MH, Nagiah S. Over-imaging in uncomplicated low back pain: a 12-month audit of a general medical unit. Intern Med J. 2016;46:1437-9.

16. Jame SZ, Sari AA, Majdzadeh R, et al. The extent of inappropriate use of magnetic resonance imaging in low back pain and its contributory factors. Int J Prev Med. 2014;5:1029-36.

17. Gidwani R, Sinnott P, Avoundjian T, et al. Inappropriate ordering of lumbar spine magnetic resonance imaging: are providers choosing wisely? Am J Manag Care. 2016;22:e68-76.

18. Emery DJ, Shojania KG, Forster AJ, et al. Overuse of magnetic resonance imaging. JAMA Intern Med. 2013;173:823-5.

19. Avoundjian T, Gidwani R, Yao D, et al. Evaluating two measures of lumbar spine MRI overuse: administrative data versus chart review. J Am Coll Radiol. 2016;13:1057-66.

20. Oikarinen H, Meriläinen S, Pääkkö E, et al. Unjustified CT examinations in young patients. Eur Radiol. 2009;19:1161-5.

21. Wiesel SW, Tsourmas N, Feffer HL, Citrin CM, Patronas N. A study of computer-assisted tomography. I. The incidence of positive CAT scans in an asymptomatic group of patients. Spine. 1984;9:549-51.

22. Boden SD, Davis DO, Dina TS, Patronas NJ, Wiesel SW. Abnormal magnetic-resonance scans of the lumbar spine in asymptomatic subjects: a prospective investigation. J Bone Joint Surg Am. 1990;72:403-8
23. Jensen MC, Brant-Zawadzki MN, Obuchowski N, Modic MT, Malkasian D, Ross JS. Magnetic resonance imaging of the lumbar spine in people without back pain. N Engl J Med. 1994;331:69-73.

24. Borenstein DG, O'Mara JW Jr, Boden SD, et al. The value of magnetic resonance imaging of the lumbar spine to predict lowback pain in asymptomatic subjects: a 7-year follow-up study. J Bone Joint Surg Am. 2001;83-A:1306-11.

25. Troyanovich SJ, Harrison DD, Harrison DE. Low back pain and the lumbar intervertebral disk: clinical considerations for the doctor of chiropractic. J Manip Physiol Ther. 1999;22(2):96-104.

26. Coppes MH, Marani E, Thomeer RT, Oudega M, Groen GJ. Innervation of annulus fibrosus in low back pain. Lancet. 1990;336:189-90.

27. Freemont AJ, Peacock TE, Goupille P, Hoyland JA, O’Brien J, Jayson MIV. Nerve ingrowth into diseased intervertebral disc in chronic back pain. Lancet. 1997;350:178-81.

28. Manchikanti L, Hirsch JA. An update on the management of chronic lumbar discogenic pain. Pain Manag. 2015;5(5):373-86.

29. O'Neill C, Kurgansky M, Kaiser J, Lau W. Accuracy of MRI for diagnosis of discogenic pain. Pain Physician. 2008;11(3):311-26.

30. Peng B, Hou S, Wu W, Zhang C, Yang Y. The pathogenesis and clinical significance of a high-intensity zone (HIZ) of lumbar intervertebral disc on MR imaging in the patient with discogenic low back pain. Eur Spine J. 2006;15(5):583-7.

31. Aprill C, Bogduk N. High-intensity zone: a diagnostic sign of painful lumbar disc on magnetic resonance imaging. Br J Radiol. 1992;65:361-9.

32. Panjabi M. The stabilizing system of the spine. Part II. Neutral zone and instability hypothesis. J Spinal Disord. 1992;5(4):390-6. https://doi.org/10.1097/00002517-199212000-00002.

33. Panjabi M, Lydon C, Vasavada A, Grob D, Crisco JJ 3rd, Dvorak J. On the understanding of clinical instability. Spine. 1994;19(23):2642-50.

34. O'Sullivan BP. Lumbar segmental instability: clinical presentation and specific stabilizing exercise management. Man Ther. 2000;5:2-12.

35. Park AL. Instability: clinical manifestations and assessment. In: Slipman CW, Derby R, Simeone FA, Mayer TG, editors. Interventional spine an algorithmic approach. Philadelphia: Saunders; 2008. p. 1109-19.

36. Kirkaldy-Willis WH, Farfan HF. Instability of the lumbar spine. Clin Orthop Relat Res. 1982;165:110-23.

37. Jinkins JR. Acquired degenerative changes of the intervertebral segments at and suprajacent to the lumbosacral junction. A radioanatomic analysis of the nondiscal structures of the spinal column and perispinal soft tissues. Eur J Radiol. 2004;50(2):134-58.

38. Bogduk N. Clinical and radiological anatomy of the lumbar spine. 5th ed. Edinburgh: Churchill Livingstone Elsevier; 2012. p. 207-15.

39. Kotilainen E, et al. Clinical instability of the lumbar spine after microdiscectomy. Acta Neurochir. 1993;125:120-6.

40. Eisenstein SM, Parry CR. The lumbar facet arthrosis syndrome. J Bone Joint Surg. 1987;69B:3.

41. Schwarzer AC, Wang SC, O'Driscoll D, et al. The ability of computed tomography to identify a painful zygapophysial joint in patients with chronic low back pain. Spine. 1995;20:907-12.

42. Schutz U, Cakir B, Dreinhofer K, Richter M, Koepp H. Diagnostic value of lumbar facet joint injection: a prospective triple cross-over study. PLoS One. 2011;6(11):e27991. https://doi.org/10.1371/journal.pone.0027991.

43. Pneumaticos SG, Chatziioannou SN, Hipp JA, Moore WH, Esses SI. Low back pain: prediction of short-term outcome of facet joint injection with bone scintigraphy. Radiology. 2006;238:693-8.

44. Cook NJ, Hanrahan P, Song S. Paraspinal abscess following facet joint injection. Clin Rheumatol. 1999;18(1):52-3.

45. Alcock E, Regaard A, Browne J. Facet joint injection: a rare form cause of epidural abscess formation. Pain. 2003;103(1-2):209-10. 
46. Okazaki K, Sasaki K, Matsuda S, Yuge I, Omiya K, et al. Pyogenic arthritis of a lumbar facet joint. Am J Orthop. 2000;29(3):222-4.

47. Saal JS. General principles of diagnostic testing as related to painful lumbar spine disorders: a critical appraisal of current diagnostic techniques. Spine. 2002;27(22):2538-46.

48. Schwarzer AC, Aprill CN, Derby R, Fortin J, Kine G. The falsepositive rate of uncontrolled diagnostic blocks of the lumbar zygapophysial joints. Pain. 1994;58(2):195-200.

49. Murtagh R. The art and science of nerve root and facet blocks. Neuroimaging Clin N Am. 2000;10(3):465-77.

50. Van Kleef M, Barendse GA, Kessels A, Voets HM, Weber WE, et al. Randomized trial of radio frequency lumbar facet denervation for chronic low back pain. Spine. 1999;24:1937-42.

51. Gregory DS, Seto CK, Wortley GC, Shugart CM. Acute lumbar disk pain: navigating evaluation and treatment choices. Am Fam Physician. 2008;78(7):835-42.

52. Sembrano JN, Polly DW. How often is low back pain not coming from the back? Spine (Phila Pa 1976). 2009;34(1):E27-32.

53. Cohen SP. Sacroiliac joint pain: a comprehensive review of anatomy, diagnosis, and treatment, and treatment. Anesth Analg. 2005;10(5):1440-53.

54. Schwarzer AC, Aprill CN, Bogduk N. The sacroiliac joint in chronic low back pain. Spine. 1995;20:31-7.

55. Maigne JY, Aivaliklis A, Pfefer F. Results of sacroiliac joint double block and value of sacroiliac pain provocation tests in 54 patients with low back pain. Spine. 1996;21:1889-92.

56. Bernard TN, Cassidy JD. The sacroiliac syndrome. Pathophysiology, diagnosis and management. In: Frymoyer JW, editor. The adult spine: principles and practice. New York: Raven; 1991. p. 2107-30.

57. Laslett M. Evidence-based diagnosis and treatment of the painful sacroiliac joint. J Man Manip Ther. 2008;16(3):142-52.

58. Ivanov AA. Lumbar fusion leads to increases in angular motion and stress across sacroiliac joint: a finite element study. Spine. 2009;34(5):162-9.

59. Murata Y, Takahashi K, Yamagata M, et al. Sensory innervation of the sacroiliac joint in rats. Spine. 2000;25(16):2015-9.

60. Grob KR, Neuhuber WL, Kissling RO. Innervation of the sacroiliac joint in humans. Z Rheumatol. 1995;54:117-22.

61. Ikeda R. Innervation of the sacroiliac joint: macroscopic and histological studies. J Nippon Med Sch. 1991;58:587-96.

62. Fortin JD, Kissling RO, O’Connor BL, Vilensky JA. Sacroiliac joint innervations and pain. Am J Orthop. 1999;28:68-90.

63. Cohen SP, Pain SJ. A comprehensive review of anatomy, diagnosis, and treatment. Anesth Analg. 2005;101:1440-53.

64. Ross JS, Robertson JT, Frederickson RC, Petrie JL, Obuchowski N, Modic MT, de-Tribolet N. Association between peridural scar and recurrent radicular pain after lumbar discectomy: magnetic resonance evaluation. Neurosurgery. 1996;38:855-63.

65. Jou IM, Tai TW, Tsai CL, Tsai TM, Yung WS, Jung YC. Spinal somato sensory evoked potential to evaluate neurophysiologic changes associated with postlaminotomy fibrosis: an experimental study. Spine (Phila Pa 1976). 2007;32:2111-8.

66. Cooper RG, Freemont AJ, Hoyland JA, Jenkins JP, West CG, Illingworth KJ, Jayson MI. Herniated intervertebral disc associated periradicular fibrosis and vascular abnormalities occur without inflammatory cell infiltration. Spine (PhilaPa 1976). 1996;20:591-8.

67. Blond S, Mertens P, David R, Roulaud M, Rigoard P. From "mechanical" to "neuropathic" back pain concept in FBSS patients. A systematic review based on factors leading to the chronification of pain (part C). Neurochirurgie. 2015;61(Suppl 1):S45-56.

68. Fras C, Kravetz P, Mody DR, Heggeness MH. Substance P-containing nerves within the human vertebral body: an immunohistochemical study of the basivertebral nerve. Spine J. 2003;3(1):63-7.

69. Bailey JF, Liebenberg E, Degmetich S, Lotz JC. Innervation patterns of PGP 9.5-positive nerve fibers within the human lumbar vertebra. J Anat. 2011;218(3):263-70.

70. Antonacci MD, Mody DR, Heggeness MH. Innervation of the human vertebral body: a histologic study. J Spinal Disord. 1998;11(6):526-31.

71. Luoma K, Vehmas T, Grönblad M, et al. Relationship of Modic type 1 change with disc degeneration: a prospective MRI study. Skelet Radiol. 2009;38:237-44.

72. Luoma K, Vehmas T, Grönblad M, et al. MRI follow-up of subchondral signal abnormalities in a selected group of chronic low back pain patients. Eur Spine J. 2008;17:1300-8.

73. Kääpä E, Luoma K, Pitkäniemi J, Kerttula L, Grönblad M. Correlation of size and type of modic types 1 and 2 lesions with clinical symptoms: a descriptive study in a subgroup of patients with chronic low back pain on the basis of a university hospital patient sample. Spine. 2012;37(2):134-9. https://doi.org/10.1097/ BRS.0b013e3182188a90.

74. Russo VM, Dhawan RT, Dharmarajah N, Baudracco I, Lazzarino AI, Casey AT. Hybrid bone single photon emission computed tomography imaging in evaluation of chronic low back pain: correlation with modic changes and degenerative disc disease. World Neurosurg. 2017;104:816-23. https://doi.org/10.1016/j. wneu.2017.03.107.

Open Access This chapter is licensed under the terms of the Creative Commons Attribution 4.0 International License (http://creativecommons. org/licenses/by/4.0/), which permits use, sharing, adaptation, distribution and reproduction in any medium or format, as long as you give appropriate credit to the original author(s) and the source, provide a link to the Creative Commons license and indicate if changes were made.

The images or other third party material in this chapter are included in the chapter's Creative Commons license, unless indicated otherwise in a credit line to the material. If material is not included in the chapter's Creative Commons license and your intended use is not permitted by statutory regulation or exceeds the permitted use, you will need to obtain permission directly from the copyright holder. 